\title{
Open Access là tương lai của khoa học
}

\author{
Hoàng Phương Hạnh \\ Viện Khoa học Giáo dục Việt Nam
}

Hồ Mạnh Toàn

A.I. for Social Data Lab, SSHPA System

Version 2

Hà Nội, 03-03-2019

Kể từ khi Plan S được Robert-Jan Smits đề xuất hồi tháng 9 năm 2018 đã khiến chuyển động của thế giới khoa học về vấn đề Open Access ngày một mạnh mẽ hơn. Plan $\mathrm{S}$ hiện được các nhà nghiên cứu, các quỹ tài trợ ủng hộ hết mình bất chấp sự chần chừ của nhiều nhà xuất bản. Trong khi đó, các mô hình xuất bản mới, các hệ thống preprints, nền tảng chia sẻ nghiên cứu Research Gate vẫn luôn sẵn sàng hỗ trợ các nhà khoa học trong công cuộc giải phóng tri thức.

\section{Plan $S$ và các nhà xuất bản}

Kế hoạch khoa học mở hoàn toàn Plan $\mathrm{S}$ đang khiến các nhà xuất bản trầy trât với chính sách cứng rắn của mình [1]. Các nhà xuất bản, bao gồm cả những cái tên nổi tiếng như Nature hay Science, dù đồng ý với Plan S nhưng vẫn cho rằng các chi tiết liên quan đến tạp chí 'lai', phí xuất bản (APC) công bằng cần được xem xét lại. Chi phí sản xuất nghiên cứu hiện tại (có thể lên tới US\$40000) là một trong những lí do nổi bật nhất. Bên cạnh đó, thời điểm 2020 cũng được cho là quá gấp gáp để các tạp chí có thể chuyển đổi mô hình hoạt động một cách trọn vẹn. Chi phí lớn của việc chuyển đổi nhanh sẽ dẫn đến việc tăng APC, giảm thiểu chất lượng. 


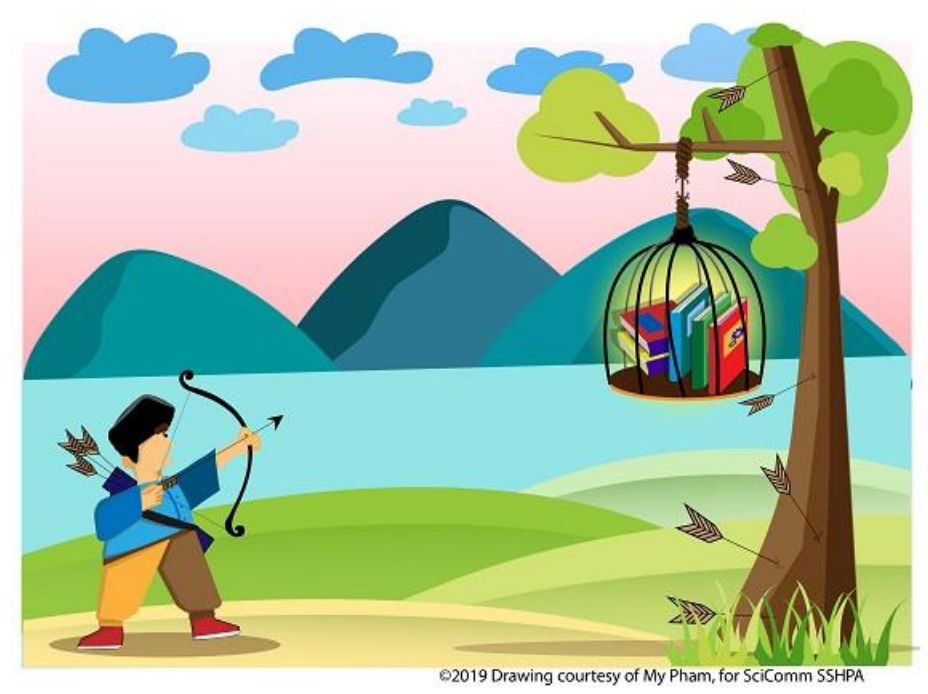

Theo nhà Sinh lý hoc và Y khoa đạt giải Nobel Randy Schekman—cựu tổng biên tập tạp chí eLife-thì các nhà xuất bản có phần phản đối lại Open Access vì điều này ảnh hưởng đến biên lợi nhuận của họ [2]. Tuy nhiên, người dân trả tiền cho các nghiên cứu thì họ nên có quyền được truy cập nó miễn phí. Các chi phí sản xuất khoa học thì nên được công bố rõ ràng [3].

Trả lời các ý kiến này của các nhà xuất bản, kiến trúc sư trưởng của Plan SRobert-Jan Smits-thẳng thắn đánh giá các tạp chí nên có một mô hình kinh doanh mới. Ông cũng hy vọng sẽ có thể nhóm họp với đại diện các nhà xuất bản, các nhà tài trợ để có thể đưa ra các nguyên tắc chung; tuy nhiên, các nguyên tắc này chắc chắn sẽ không có chuyện giá cả [1].

\section{Mô hình xuất bản hợp lí}

Có thể thấy, mô hình xuất bản do Robert Maxwell phát triển đang ngày một thể hiện sự yếu thế của mình. Tờ The Guardian thậm chí còn gọi đây là một trong những thương vụ lừa đảo lớn nhất trong thời hiện đại [4]. Để chống lại sự độc quyền tri thức công, các mô hình theo hướng Open Access khác nhau đã đã được các tạp chí như PeerJ (2017 JIF=2.118; CiteScore = 2.38), F1000Research $(2017$ CiteScore $=1.59)$, hay eLife $(2017 \mathrm{JIF}=7.616$; CiteScore $=6.88)$ thử nghiệm. PeerJ cho phép các nhà nghiên cứu công bố miễn phí theo cấp độ từ 1,2 , đến 5 nghiên cứu một năm thông qua các gói đăng kí gói thành viên trọn đời. Trong khi đó, tạp chí F1000Research lại hướng đến mô hình Open Access hoàn toàn: phản biện, bản thảo, dữ liệu, các phiên bản nghiên cứu. 


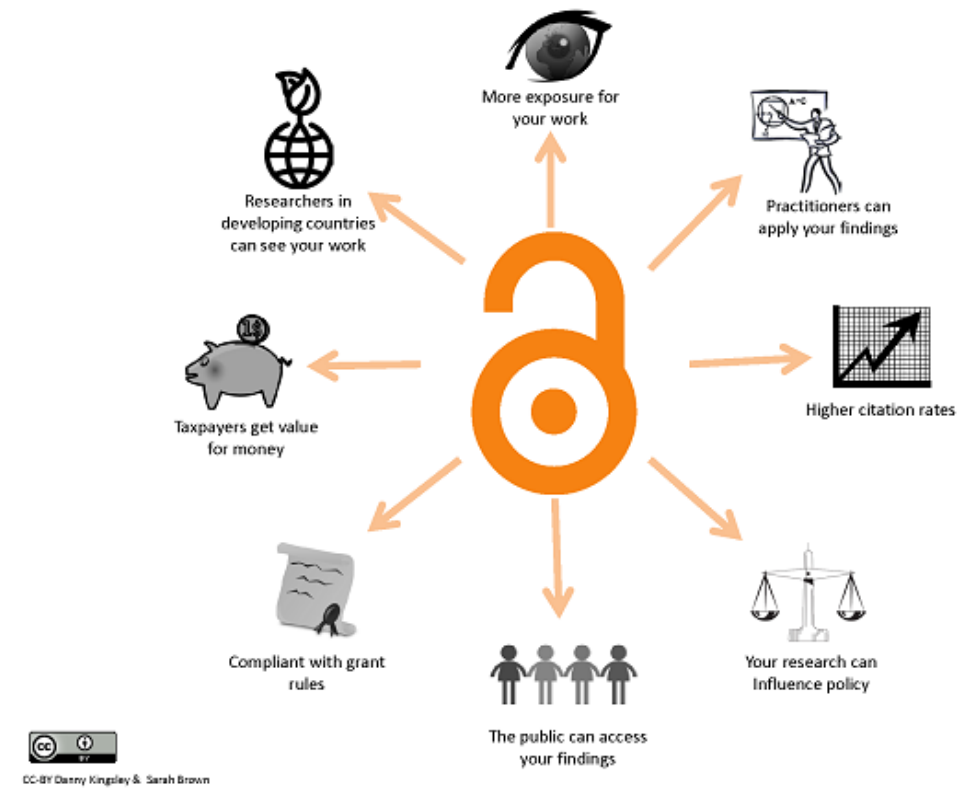

(Nguồn: CC-BY Danny Kingsley \& Sarah Brown)

Tờ eLife do Randy Schekman sáng lập năm 2012 thì lại có hệ thống hợp tác phản biện mở độc đáo. Các nhà nghiên cứu còn được xuất bản miễn phí trong suất 5 năm đầu tiên của eLife, cho đến khi tạp chí cần ngân sách để tiếp tục phát triển. Trả lời phỏng vấn trên Nature, Randy Schekman cho biết việc hợp tác phản biện mở giúp đảm bảo chất lượng và căn cứ của các ý kiến phản biện khi danh tính của các bình duyệt viên được công khai [2]. Thêm vào đó, các biên tập viên có thể tổng hợp và chỉnh lý lại nội dung phản biện sao cho rõ ràng và hữu ích nhất đối với tác giả. Trước những ý kiến quan ngại về quy trình mới như việc gia tăng lượng công việc cho các bình duyệt viên cũng như tính chân thực và khách quan của các ý kiến phản biện trước tương quan danh tính và vị thế khoa học của các bình duyệt viên và tác giả, cựu trưởng ban biên tập của eLife cho hay ông có cách nhìn tương đối lạc quan. Bên cạnh các tạp chí mở, Randy cũng cho biết các hêe thống preprints cũng đang dần thay đổi hệ thống xuất bản. Điển hình như bioRxiv đã có đến hơn 30 nghìn bản thảo chỉ sau 5 năm hoạt động.

Bên cạnh các mô hình tạp chí mới, rõ ràng các hệ thống preprints như OSF, bioRxiv, hay nền tảng chia sẻ nghiên cứu Research Gate đã và đang đóng góp một phần không nhỏ cho việc thúc đẩy Open Access.

\section{Springer Nature hợp tác với Research Gate}

6h chiều Việt Nam ngày 1 tháng 3 năm 2019, nhà xuất bản Springer Nature đã công bố chính thức chương trình hợp tác tiên phong của mình với mạng xã hội chuyên biệt cho các nhà khoa học Research Gate [5]. Theo đó, toàn văn nghiên cứu của một số tạp chí trong hệ thống Nature Research sẽ có thể truy cập được từ hồ sơ khoa học trên ResearchGate. Dự kiến đến ngày 7 tháng 3 , chương trình này sẽ được hoàn tất và giúp các nhà nghiên cứu truy cập các bài báo ngay cả khi không ở trong khuôn viên viện hoặc trường đại học. 
Đây là kết quả của thỏa thuân được kí kết hồi tháng 4-2018 giữa Research Gate và ba nhà xuất bản: Springer Nature, Cambridge University Press, và Thieme [6]. Thỏa thuận này giúp các nhà xuất bản nắm vững được tình hình chia sẻ các tài liệu của mình được chia sẻ trên nền tảng Research Gate, đồng thời cũng giải quyết các vấn đề liên quan đến bản quyền cho mạng xã hội này. Hồi tháng 10 năm 2017, vấn đề bản quyền đã khiến Research Gate bị gã khổng lồ Elsevier dần cho một trận tưởng suýt tắt thở [7]. Trước đó nữa, một nền tảng tương tự là Academia.edu cũng được Elsevier 'dằn mặt'.

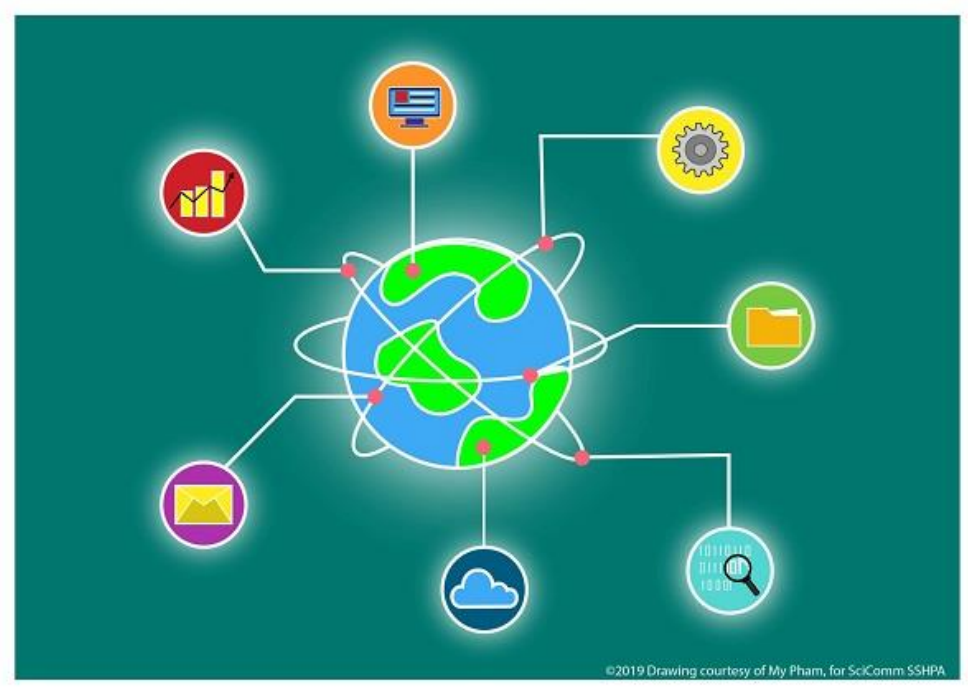

Trưởng bộ phận xuất bản của Springer Nature, Steven Inchcoombe hy vọng chương trình tiên phong này sẽ giúp mang đến cho các nhà khoa học chia sẻ được các nghiên cứu với đồng nghiệp, thúc đẩy hợp tác và phát triển. Trong khi đó, CEO của Research Gate Ijad Madisch thì hy vọng sự hợp tác giữa hệ thống xuất bản hàng đầu của Springer Nature và mạng lưới hơn 15 triệu nhà khoa học của Research Gate sẽ tạo ra các điều kiện lý tưởng hơn nữa cho hợp tác khoa học.

\section{Open Access là tương lai của khoa học}

Hiện nay Plan S đều đã được Trung Quốc và hai quỹ tài trợ lớn là Wellcome Trust và Bill \& Melinda Gates Foundation tuyên bố ủng hộ. Sự cứng rắn của Plan $\mathrm{S}$ và vị kiến trúc sư trưởng cũng khiến các nhà xuất bản trầy trật. Có thể thấy, dù Springer Nature có phần phản ứng trước chính sách của Plan $S$ thì động thái tiên phong với Research Gate diễn ra cùng thời điểm cũng cho thấy nhà xuất bản này đang đưa ra những phương án phù hợp.

Hiện nay, một số trở ngại cho Open Access đến từ sự cứng rắn của các nhà xuất bản như Elsevier khi đàm phán giữa họ và các nhà nghiên cứu gặp bế tắc; hay các động thái tấn công các nền tảng chia sẻ như Research Gate. Bên cạnh đó, cũng vẫn còn nhiều nhà khoa học đánh đồng Open Access với hành vi săn mồi, trục lợi của nhiều tạp chí thiếu uy tín.

Tuy nhiên, như cựu tổng biên tập của eLife nhận xét: "Open Access is the future". Tri thức của nhân loại chắc chắn không thể bị giam cầm phía sau 'tường thành chi phí được. 
Note: Published in $\underline{\text { SciComm SSHPA. }}$

\section{References:}

[1] Else, H. (2019). High-profile subscription journals critique Plan S. Nature, doi: 10.1038/d41586-019-00596-x.

URL: https://www.nature.com/articles/d41586-019-00596-x.

[2] Else, H. (2019). Open-access pioneer Randy Schekman on Plan S and disrupting scientific publishing. Nature, doi: 10.1038/d41586-019-00595-y. URL: https://www.nature.com/articles/d41586-019-00595-y.

[3] Vuong, Q. H. (2018). The (ir)rational consideration of the cost of science intransition economies. Nature Human Behaviour, 2(1), 5, DOI:10.1038/s41562-017-0281-4.

[4] Monbiot, G. (2018). Scientific publishing is a rip-off. We fund the research - it should be free. The Guardian. URL: https://www.theguardian.com/commentisfree/2018/sep/13/scientificpublishing-rip-off-taxpayers-fund-research.

[5] Springer Nature. (2019). ResearchGate and Springer Nature embark on pilot to deliver seamless discovery and an enhanced the reading experience. Press Release. URL: https://group.springernature.com/gp/group/media/pressreleases/researchgate-and-springer-nature-embark-on-pilot/16518868.

[6] Trager, R. (2018). ResearchGate reaches deal with science publishers. Chemistry World. URL: https://www.chemistryworld.com/news/researchgate-reaches-dealwith-science-publishers/3008943.article.

[7] Chawla, D. S. (2017). Publishers take ResearchGate to court, alleging massive copyright infringement. Science, doi:10.1126/science.aaq1560. 